\title{
POTENTIAL OF UPUNA BORNEENSIS AND SHOREA LONGISPERMA SEED EXTRACTS AGAINST COPTOTERMES GESTROI
}

\author{
Roszaini K*, Nashatul-Zaimah NA \& Noor-Azah MA \\ Forest Research Institute Malaysia, 52109 Kepong, Kuala Lumpur, Malaysia \\ *roszaini@frim.gov.my
}

Submitted May 2019; accepted September 2019

\begin{abstract}
Toxicity and repellency of Upuna borneensis and Shorea longisperma seed extracts were evaluated against the subterranean termite, Coptotermes gestroi. Chemical composition of the seed extracts was examined by GC-MS. A total of 17 compounds were extracted from the cotyledon of $S$. longisperma and another 17 were obtained from the seed coat whereas 12 and 14 compounds were extracted from the cotyledon and seed coat of $U$. borneensis respectively. The major compound in S. longisperma cotyledon extract was Germacra-4(15),5,10(14)-trien-1alpha-ol, while the major compounds in seed coat extract were Dihydro-eugenol acetate, $B$-Thujaplicinol and Torulosol. Upuna borneensis cotyledon extract contained four major compounds: 2,4,6-Trimethoxy-toluene, Syringaldehyde, B-Cyclocitral and Allo-cedrol, while three compounds were identified from the seed coat extract: 2'-Hydroxyacetophenone, Methyl p-tert-butylphenylacetate and Iso-Jasmone. Cotyledon and seed coat extracts of $U$. borneensis showed strong repellency against C. gestroi. Conversely, cotyledon and seed coat extracts of $S$. longisperma, attracted more termites at higher concentrations. The results suggested that extract of wasted seeds might be used as candidates in termite control (repellents, anti-repellent or antifeedant).
\end{abstract}

Keywords: Termiticidal, seed extract, subterranean termite, seed coat, cotyledon

\section{INTRODUCTION}

Wood can give many years of excellent service if it is properly treated/preserved with biocidal compounds. However, the public is increasingly concerned about the harmful environmental effects of a number of excellent wood preservatives such as chromated copper arsenate. Malaysia, due to its humid weather, loses valuable wood in service as a result of insect attacks and other biodegrading agents. Each year, massive economic losses resulting from the maintenance and repair of wood structures can be attributed to termite attack.

In recent years, much research has focused on the development of safer wood preservatives which are toxic against wood damaging agents but have minimal impact on the environment. This research includes many plant-derived compounds that are considered to be eco-friendly (Antwi-Boasiako \& Damoah 2010). Plant-derived materials are known to be effective against insect pests (George et al. 2014), inciting investigators to screen for their toxic effects for use as insecticides (Singh \& Singh 2012).
The use of seed extracts for wood preservation has been reported before as many of these compounds have anti-termite and repellent properties (Yang 2009). For example, using treated filter papers, Jatropha curcas seed extract at different concentration (20,30 and $\left.35 \mathrm{~g} \mathrm{~mL}^{-1}\right)$ and Azadirachta indica $\left(35 \mathrm{~g} \mathrm{~mL}^{-1}\right)$ killed $100 \%$ of Macrotermes spp. workers after 72 hours of exposure in laboratory conditions ( $25 \pm 3{ }^{\circ} \mathrm{C}$ and $60-70 \%$ relative humidity) (Addisu et al. 2014). Other studies found varying degrees of termiticidal activity of Parkia biglobosa seed extract against Coptotermes intermedius and antitermitic activities of Mentha arvensis, Ocimum bacilicum, Plantago ovate and Cichorium intybus against Coptotermes heimi (Olugbemi 2012, Aihetasham et al. 2016). Even at a low concentration of $1 \%$, extract of Jatropha curcas seeds was proven to be effective against Microcerotermes beesoni (Singh \& Sushilkumar 2008).

Upuna borneensis is an endangered monotypic plant from the family of Dipterocarpaceae. It is endemic to Borneo and commonly known as 
upun, upun batu, penyau, balau penyau, cangal tanduk or penyau tanduk. It is a large tree with low stout buttress. The bark is dark brown, finely flaky with non-laminated inner bark. The wood is commonly used for construction, heavyduty furniture, railway sleepers and boat making due to its high density (945-1040 $\mathrm{kg} \mathrm{m}^{-3}$ at $15 \%$ moisture content) (Wong 1982). Upuna borneensis has more than 14 resveratrol derivatives, including upunaphenols B (1), C (4), D (5) (resveratrol tetramer) and $\mathrm{E}$ (6, resveratrol dimmer with a C6-C1 unit), which were isolated from acetonesoluble part of its stem (Ito et al. 2005). Stilbenes (resveratrol) which are present in many naturally durable woods have been associated with the durability of heartwood (Schultz \& Nicholas 2000, Hassan et al. 2018). Resveratrol causes weight reduction of the groundnut pests, Spodoptera litura and Amsacta albistriga, and attracts the egg parasitoid Trichogramma chilonis under laboratory conditions (Sambangi \& Rani 2016).

Shorea longisperma, commonly known as meranti damar hitam, is a threatened timber tree also in the family Dipterocarpaceae. Shorea longisperma has large, diffuse, cauliflower-shaped crown that can grow up to $70 \mathrm{~m}$ tall. The tall, straight, cylindrical bole can be up to $290 \mathrm{~cm}$ in diameter with stout buttresses up to $4 \mathrm{~m}$ high and extending outwards (Soepadmo et al. 2002). The wood is lightweight, soft, moderately durable but susceptible to biological attack and the density is variable $\left(370-860 \mathrm{~kg} \mathrm{~m}^{-3}\right.$ at $15 \%$ moisture content). This timber species can be found in Brunei, Indonesia (Sumatra) and Malaysia (Sarawak) (Yong et al. 2011).

Previous studies found that this genus contains ligostilbenes such as resveratrol (Ito 2011) which exhibited a variety of bioactivity including anti-termite and anti-fungal properties
(Roszaini \& Hale 2019), In this study, we analysed the chemical constituents of extracts from waste cotyledons and seed coats of $U$. borneensis and $S$. longisperma. These species were chosen because of the inability of the seeds to germinate in storage. Potential uses for these seeds that otherwise would have been wasted, were being examined. We also investigated the toxicity and repellent effects of both seed extracts against the subterranean termite, Coptotermes gestroi.

\section{MATERIALS AND METHODS}

\section{Termites}

Coptotermes gestroi (soldiers and workers) were collected from active field colonies around the Forest Research Institute Malaysia (FRIM) campus using previously described method by Kirton et al. (1998). Cardboard pieces were moistened with distilled water, stacked together in a large basin, covered with aluminium foil and placed in dark plastic bags that were attached to trees containing termite colonies for two weeks. Termites moved from the tree into the cardboard where they could be easily collected into the basin.

\section{Plant materials}

Seeds of $U$. borneensis and S. longisperma were procured from trees at the FRIM campus and stored in airtight containers. Seed coat (wing) and cotyledon were separated (Figure 1) using a knife. The cotyledon was split to get its contents. Seed coat and cotyledon were air-dried and stored in an airtight container before being separately ground to pass through 250- $\mu \mathrm{m}$ sieves.

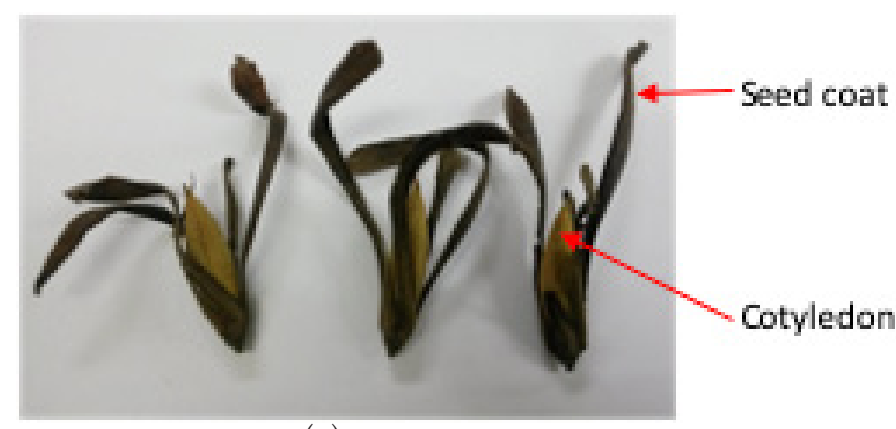

(a)

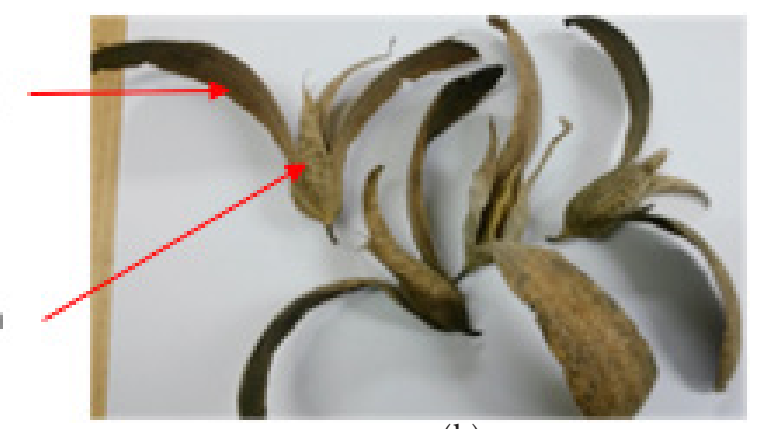

(b)

Figure 1 Seeds of Upuna borneensis (a) and Shorea longsperma (b) 


\section{Extraction}

Methanol (analytical grade) was used to extract compounds from the seed parts according to ASTM Standard D1105-96 (ASTM 2001) with slight modifications. Five replicates of $5 \mathrm{~g}$ (airdried at $103 \pm 5{ }^{\circ} \mathrm{C}$ ) of ground seed part were weighed to the nearest $0.1 \mathrm{mg}$, then extracted using $240 \mathrm{~mL}$ methanol in a pre-weighed cellulose thimble (porosity 1, height $95 \mathrm{~mm}$ ) for 5 hours (4-6 siphons hour ${ }^{-1}$ ) in a Soxhlet extractor. The collected solvent extract was then filtered and the filtrate was evaporated to dryness under reduced pressure at $45^{\circ} \mathrm{C}$ using vacuum rotary evaporator. The dried extract was used to produce a series of concentrations. The extracts were stored in small vials at room temperature.

\section{Chemical analysis}

The chemical composition of the extract was analysed by gas chromatography and gas chromatography mass spectrometry (GC-MS) at similar temperature conditions and parameters as previously described (Roszaini et al. 2013). Quantitative analysis was carried out using GC or GC-MS equipped with fused silica capillary columns CBP5 $(25 \mathrm{~m} \times 0.25 \mathrm{~mm} \times 0.25 \mathrm{~mm})$ or HP-5MS column $(30 \mathrm{~m} \times 0.25 \mathrm{~mm} \times 0.25 \mathrm{~mm})$ respectively. The GC was equipped with a flame ionisation detector using split-mode injection technique, and the operating parameters were helium gas as the carrier gas at a flow rate of $1 \mathrm{~mL} \mathrm{~min}{ }^{-1}$, an injector temperature of $250^{\circ} \mathrm{C}$ and a detector temperature of $250^{\circ} \mathrm{C}$. With the CBP5 column, the GC was programmed initially at $60^{\circ} \mathrm{C}$ for $10 \mathrm{~min}$, followed by $230^{\circ} \mathrm{C}$ for $1 \mathrm{~min}$ at $3{ }^{\circ} \mathrm{C} \mathrm{min}^{-1}$. The temperature programme for $\mathrm{GC}$ MS analysis was set similar to the GC programme. Major chemical constituents were identified by comparison of their retention indices with the literature values (Adam 2001) and their mass spectral data with those of the mass spectral database.

\section{Toxicity assay}

The method described by Roszaini et al. (2014) was employed to assess the efficacy of extracts against termites. Dried extracts diluted with methanol were tested at concentrations of $0.5,1$, 2, 3 and $4 \%$. The solutions were applied to filter papers discs $(9.0 \mathrm{~cm}$ diameter and $1.5 \mathrm{~mm}$ thick) and dried in laminar air flow for 1 hour. The weight of filter paper was measured before and after treatment. Untreated filter paper and filter paper treated with methanol served as controls with each of the tests repeated three times. Fifty active $C$. gestoi ( 45 workers and 5 soldiers from third instar) were introduced into each Petri dish $(9.1 \mathrm{~cm}$ diameter and $1.6 \mathrm{~cm}$ height $)$. A few drops of water were added periodically to the bottom edge of each Petri dish. The Petri dishes were placed in an incubator in darkness at $26 \pm 2{ }^{\circ} \mathrm{C}$ and $65 \pm 5 \%$ relative humidity. Termite mortality was recorded every 24 hours until $100 \%$ mortality was observed. Dose-mortality was developed based on exposure time and the lethal concentration required to kill at least half of the termites exposed $\left(\mathrm{LC}_{50}\right)$. Probit analysis was used for wood extract concentrations series tested (Finney 1971).

\section{Repellence assay}

The ability of the extracts to repel termites was assessed according to McDonald et al. (1970) with some modifications. An amount of $1 \mathrm{~mL}$ extracts at different concentrations (diluted with methanol) was applied to half the surface of the $9 \mathrm{~cm}$ diameter filter paper (the filter paper was cut into two) while the other half was treated with $1 \mathrm{~mL}$ methanol. The Petri dishes were dried in a laminar flow hood for one hour and treated and control halves were attached with adhesive tape. Each dish was placed in a $9.1 \mathrm{~cm}$ diameter Petri dish and 50 workers of C. gestroi were put in the centre of each dish. The number of termites present in the control (NC) and the treated halves $(\mathrm{Nt})$ was assessed hourly for 4 hours. The percentage of repellent was calculated using the formula below:

$$
\begin{aligned}
& \text { Repellent percentage }= \\
& \quad[(\mathrm{Nc}-\mathrm{Nt}) /(\mathrm{Nc}+\mathrm{Nt})] \times 100
\end{aligned}
$$

\section{Statistical analysis}

The formula by Abbott (1925) was used for the probit analyses. Changes in properties of treated and untreated specimens were evaluated using a one-way analysis of variance. The effects of concentration of extractives on weight loss, density and feeding inhibition were determined. Duncan's multiple range test was used for ranking of the average values of the measured property. 


\section{RESULTS AND DISCUSSION}

\section{Extract yields}

Table 1 shows the yield of extracts produced using the solvent system. Cotyledon and seed coats from $U$. borneensis produced greater extract yields than $S$. longisperma seeds. Upuna borneensis cotyledon produced the highest yield $(14.31 \%)$ while $S$. longisperma cotyledon, the lowest $(6.58 \%)$. Variation in extract yield and chemical composition of extracts depends on several factors including growing conditions, wood species (different timber has different characteristics), differences between trees of the same species and within the tree itself (different anatomical structure), the products and reagents used in the extraction, method of extraction, drying temperature, conditions, temperature and time (Xu et al. 2009).

\section{Chemical compounds}

Chemical composition of S. longisperma and $U$. borneensis cotyledon and seed coat extracts are presented in Tables 2 and 3. The analysis of $S$. longisperma cotyledon extracts revealed that Germacra-4(15),5,10(14)-trien-1-alpha-ol $(16.11 \%)$, Spathulenol (9.88\%), 10-Epi-Cubebol $(9.81 \%)$, Allo-Aromadendrene epoxide $(9.15 \%)$, 3-Thujopsanone $(8.00 \%)$, Allo-Cedrol $(6.72 \%)$, 6Z, 10E-Pseudo phytol (6.46\%), Methyl p-tertbutylphenylacetate $(6.00 \%)$ and Z-Caryophyllene $(5.76 \%)$ were the main components. Eugenol acetate $(40.71 \%)$, B-Thujaplicinol $(19.83 \%)$, Torulosol $(13.11 \%)$ and trans-Pinane $(7.85 \%)$ were the main components for $S$. longisperma seed coat.

Table 3 shows the 26 compounds identified from $U$. borneensis seed extracts. 2,4,6-TrimethoxyToluene (17.92\%), Syringaldehyde (16.49\%),
Allo-Cedro (16.36\%), B-Cyclocitral (12.18\%), Presilphiperfolan-8-ol (9.92\%), Carvacrol, $(8.96 \%)$ and Cis-Vertocitral C $(5.27 \%)$ were the major constituents identified in $U$. borneensis cotyledon extracts. Of the 14 compounds identified from seed coat extract of $U$. borneensis, eight compounds were the main components: 2'-Hydroxyacetophenone $(19.01 \%)$, Methyl p-tert-butylphenylacetate $(14.84 \%)$, Iso-Jasmone $(13.02 \%)$, Methyl linoleate $(9.04 \%)$, Methyl hexadecanoate $(8.51 \%)$, Incensole oxide $(6.52 \%)$, Methyl vanillin $(6.08 \%)$ and Hillyl acetate $(5.43 \%)$.

\section{Toxicity}

Seed extracts of both species were toxic to the subterranean termite; C. gestroi. The amount of filter paper consumed by termites was lower for filter paper treated with different concentrations of seed extracts of both $U$. borneensis and $S$. longisperma than control papers (Table 4). This meant that termites consumed smaller amount of treated paper because the extracts were poisonous to them.

Theoretically, as the concentration of a substance increases, the more constituent content is present in the liquid. If the substance is toxic, the more concentrated the substance, the more toxic it will be. The results of this study were in accordance with this theory. The higher the concentration of the extracts, the lower the percentage of paper consumed. This indicated that the diet of $C$. gestroi was inhibited with the increasing concentration of the tested extract.

Table 4 also shows that even at the highest concentration tested $(4 \%)$, termites still consumed the filter paper treated with both parts of $U$. borneensis seed extracts. A higher concentration is needed to stop filter paper consumption. Unlike $U$. borneensis (at the same

Table 1 Average extract content from Shorea longisperma and Upuna borneensis seed coats or cotyledons

\begin{tabular}{lcc}
\hline \multirow{2}{*}{ Species } & \multicolumn{2}{c}{ Extract yield $(\%)$} \\
\cline { 2 - 3 } & Cotyledon & Seed coat \\
\hline S. longispema & $6.58(1.215)^{\mathrm{dc}}$ & $8.52(1.400)$ \\
U. borneensis & $14.31(0.462)^{\mathrm{a}}$ & $12.64(3.190)^{\mathrm{b}}$ \\
\hline
\end{tabular}

Values in brackets are standard deviations; percentage values followed by the same letter are not significantly different in the same group (percentage of extractive yields) at the 0.05 level of probability; $\mathrm{n}=5$ 
Table 2 Major secondary metabolite components found in extracts of S. longisperma cotyledon and seed coat

\begin{tabular}{|c|c|c|}
\hline Compound & Class of compounds & Area $(\%)$ \\
\hline \multicolumn{3}{|l|}{ Cotyledon } \\
\hline Germacra-4(15),5,10(14)-trien-1-alpha-ol & Sesquiterpenes & 16.11 \\
\hline Spathulenol & Sesquiterpenes & 9.88 \\
\hline 10-epi-Cubebol & Sesquiterpenes & 9.81 \\
\hline Allo-Aromadendrene epoxide & Sesquiterpenes & 9.15 \\
\hline 3-Thujopsanone & Sesquiterpenes & 8.00 \\
\hline Allo-Cedrol & Sesquiterpenes & 6.72 \\
\hline $6 Z, 10 E$-Pseudo phytol & Sesquiterpenes & 6.46 \\
\hline Methyl p-tert-butylphenylacetate & Ester & 6.00 \\
\hline Z-Caryophyllene & Sesquiterpenes & 5.76 \\
\hline $6 E, 10 Z$-Pseudo phytol & Sesquiterpenes & 4.11 \\
\hline Methyl nidoresedate & Ester & 3.72 \\
\hline 11,12-Dihydroxy-Valencene & Sesquiterpenes & 3.27 \\
\hline Iso-Longifolol & Sesquiterpenes & 3.18 \\
\hline Globulol & Sesquiterpenes & 3.14 \\
\hline Hillyl acetate & Ester & 3.10 \\
\hline ß-Acoradienol & Sesquiterpenes & 0.97 \\
\hline$\alpha$-Cedrene epoxide- aroma chemical & Sesquiterpenes & 0.62 \\
\hline Total detected $(\%)$ & & 100.00 \\
\hline \multicolumn{3}{|l|}{ Seed coat } \\
\hline Eugenol acetate & Phenyl propanoids & 40.71 \\
\hline ß-Thujaplicinol & Monoterpenes & 19.83 \\
\hline Torulosol & Diterpenes & 13.11 \\
\hline trans-Pinane & Monoterpenes & 7.85 \\
\hline Pogostol & Sesquiterpenes & 3.18 \\
\hline Gymnomitrol & Sesquiterpenes & 3.05 \\
\hline Thujopsan-2-alpha-ol & Sesquiterpenes & 2.85 \\
\hline Dill ether & Monoterpenes & 2.62 \\
\hline 3-Isoprophy-2-methoxypyrazine & Sesquiterpenes & 1.79 \\
\hline Geranyl anthranilate & Ester & 1.37 \\
\hline 13-epi-Dolabradiene & Diterpenes & 1.21 \\
\hline Zizanal & Sesquiterpenes & 1.06 \\
\hline 13-epi-Manool & Diterpenes & 0.91 \\
\hline Z-Coniferyl alcohol & Lignan & 0.44 \\
\hline Total detected $(\%)$ & & 99.98 \\
\hline
\end{tabular}

concentration level), only 0.58 to $0.65 \%$ of treated filter paper was eaten for $S$. longisperma cotyledon and seed coat extracts respectively. This may be due to the presence of sesquiterpenes in S. longisperma. These compounds and their analogues can act as anti-feedents or insecticidal agents in S. longisperma cotyledon and seed coat as reported by Dalia (2011) in her study of Casimiroa edulis leaf extract against Spodoptera littoralis larvae. An abundance of eugenol acetate $(40.71 \%)$ and
B-Thujaplicinol (19.83\%) was observed in the seed coat of $S$. longisperma. Sesquiterpenes have been found to illicit behavioural responses in subterranean termites (Hassan et al. 2017). For example, caryophyllene is a major compound for effective insecticidal activity against Aedes aegypti (Sullamy et al. 2011), Tribolium confusum and Callosobruchus maculatus (Abbas \& Tahere 2012) and stored product pests (Oryzaephilus surinamensi and Trogoderma granarium) (Janaki 
Table 3 Major secondary metabolite components found in the extracts of $U$. borneensis cotyledon and seed coat

\begin{tabular}{|c|c|c|}
\hline Compound & Class of compounds & Area $(\%)$ \\
\hline \multicolumn{3}{|l|}{ Cotyledon } \\
\hline 2,4,6-Trimethoxytoluene & Sesquiterpenes & 17.92 \\
\hline Syringaldehyde & Aldehyde & 16.49 \\
\hline Allo-Cedrol & Sesquiterpenes & 16.36 \\
\hline B-Cyclocitral & Sesquiterpenes & 12.18 \\
\hline Presilphiperfolan-8-ol & Sesquiterpenes & 9.92 \\
\hline Carvacrol & Monoterpenes & 8.96 \\
\hline Cis-Vertocitral C & Monoterpenes & 5.27 \\
\hline neo-Intermedeol & Sesquiterpenes & 3.40 \\
\hline Sesquithuriferol & Sesquiterpenes & 2.86 \\
\hline trans-Pinane & Monoterpenes & 2.44 \\
\hline (E,Z)-2,6-Nonadienal diethyl acetal & Aldehyde & 2.36 \\
\hline $5 E, 9 Z$ Farnesyl acetone $=$ ketones & Sesquiterpenes & 1.83 \\
\hline Total detected $(\%)$ & & 99.99 \\
\hline \multicolumn{3}{|l|}{ Seed coat } \\
\hline 2'-Hydroxyacetophenone & Phenyl propanoids & 19.01 \\
\hline Methyl p-tert-butylphenylacetate & Ester & 14.84 \\
\hline Iso-Jasmone & Monoterpenes & 13.02 \\
\hline Methyl linoleate & Alkaloid & 9.04 \\
\hline Methyl hexadecanoate & Ester & 8.51 \\
\hline Incensole oxide & Diterpenes & 6.52 \\
\hline Methyl vanillin & Aldehyde & 6.08 \\
\hline Hillyl acetate & Ester & 5.43 \\
\hline Nonenal<dimethyl acetal-(3Z)-> & Aldehyde & 4.64 \\
\hline 6Z, 10Z-Pseudo phytol & Sesquiterpenes & 4.35 \\
\hline Ethyl hydroquinone & Sesquiterpenes & 3.08 \\
\hline Cavacrol, methyl ether & Monoterpenes & 2.40 \\
\hline 4-Methoxy Stilbene & Monoterpenes & 1.64 \\
\hline$\alpha$-Alaskene & Sesquiterpenes & 1.44 \\
\hline Total detected $(\%)$ & & 100.00 \\
\hline
\end{tabular}

et al. 2018). Eugenol and eugenol acetate have toxicity against several insect pests, including termites (Coptotermes formosanus) (Cornelius \& Lax 2005). The 24-hour $\mathrm{LC}_{50}$ value for $U$. borneensis cotyledons extract was $4.71 \%$ and for seed coat, $4.81 \%$ (Table 4 ). The values for $S$. longisperma (3.01 and $3.27 \%$ respectively) were lower, and this was attributed to the higher sesquiterpenes content. The higher the total sesquiterpenes content, the higher the resistivity of the wood species.

\section{Repellency test}

Extract of $U$. borneensis seed coat showed strong repellent activities against $C$. gestroi at every concentration tested compared with cotyledon (Table 5). Cotyledon extract was only $5 \%$ repellent at $0.5 \%$ extract concentration, while seed coat extract was seven times $(36 \%)$ more active. Activity decreased to $33 \%$ for seed coat extract but continued to increase for cotyledon extract $(28 \%)$ at $1.0 \%$ of concentration. As reported by Sbeghen et al. (2002), repellent activity is not dependent on the chemical dosage. Generally, both cotyledon and seed coat extracts of $U$. borneensis showed increased repellency with the concentration of extract used-repellent activity increased with increasing concentration of the extract tested. Hence, $U$. borneensis seed extract, alone or in combination with those obtained from other termite repellent 
Table 4 Effect of extracts from $U$. borneensis and S. longisperma cotyledons and seed coats on paper consumption and feeding inhibition of C. gestroi

\begin{tabular}{|c|c|c|c|c|}
\hline Treatment & Concentration $(\%)$ & Paper consumption $(\%)$ & Feeding inhibition $(\%)^{1}$ & $\mathrm{LC}_{50}(\%)$ \\
\hline Control & & $4.36(0.44)^{\mathrm{a}}$ & & \multirow{7}{*}{4.71} \\
\hline Methanol & & $1.41(0.30)^{\mathrm{d}}$ & & \\
\hline \multirow{5}{*}{$\begin{array}{l}U . \text { borneensis } \\
\text { cotyledons }\end{array}$} & 0.5 & $2.02(0.18)^{\mathrm{b}}$ & $51.43(2.86)^{\mathrm{b}}$ & \\
\hline & 1.0 & $2.00(0.11)^{\mathrm{b}}$ & $52.38(1.65)^{\mathrm{b}}$ & \\
\hline & 2.0 & $1.55(0.32)^{c}$ & $58.10(4.36)^{\mathrm{a}}$ & \\
\hline & 3.0 & $1.48(0.34)^{\mathrm{cd}}$ & $59.05(4.36)^{\mathrm{a}}$ & \\
\hline & 4.0 & $1.38(0.23)^{\mathrm{d}}$ & $60.95(3.30)^{\mathrm{a}}$ & \\
\hline Control & & $4.36(0.44)^{\mathrm{a}}$ & & \multirow{7}{*}{4.81} \\
\hline Methanol & & $1.41(0.30)^{\mathrm{d}}$ & & \\
\hline \multirow[t]{5}{*}{ U. borneensis seed coat } & 0.5 & $2.24(0.15)^{\mathrm{b}}$ & $45.71(2.86)^{\mathrm{c}}$ & \\
\hline & 1.0 & $2.23(0.00)^{\mathrm{b}}$ & $48.57(0.00)^{\mathrm{c}}$ & \\
\hline & 2.0 & $1.86(0.35)^{\mathrm{c}}$ & $54.29(4.95)^{\mathrm{b}}$ & \\
\hline & 3.0 & $1.83(0.36)^{c}$ & $54.29(4.95)^{\mathrm{b}}$ & \\
\hline & 4.0 & $1.37(0.13)^{\mathrm{d}}$ & $60.95(1.65)^{\mathrm{a}}$ & \\
\hline Control & & $4.36(0.44)^{\mathrm{a}}$ & & \multirow{7}{*}{3.01} \\
\hline Methanol & & $1.41(0.30)^{\mathrm{c}}$ & & \\
\hline \multirow{5}{*}{$\begin{array}{l}\text { S. longisperma } \\
\text { cotyledons }\end{array}$} & 0.5 & $1.58(0.17)^{\mathrm{c}}$ & $54.29(2.86)^{\mathrm{cd}}$ & \\
\hline & 1.0 & $1.41(0.28)^{c}$ & $57.14(4.95)^{\mathrm{c}}$ & \\
\hline & 2.0 & $1.83(0.97)^{\mathrm{b}}$ & $52.38(2.88)^{\mathrm{d}}$ & \\
\hline & 3.0 & $1.10(0.55)^{\mathrm{d}}$ & $62.86(8.57)^{\mathrm{b}}$ & \\
\hline & 4.0 & $0.58(0.12)^{\mathrm{e}}$ & $68.20(1.11)^{\mathrm{a}}$ & \\
\hline Control & & $4.36(0.44)^{\mathrm{a}}$ & & \multirow{7}{*}{3.27} \\
\hline Methanol & & $1.41(0.30)^{\mathrm{c}}$ & & \\
\hline \multirow{5}{*}{$\begin{array}{l}\text { S. longisperma seed } \\
\text { coat }\end{array}$} & 0.5 & $2.18(0.25)^{\mathrm{b}}$ & $49.52(3.30)^{c}$ & \\
\hline & 1.0 & $1.39(0.14)^{\mathrm{c}}$ & $60.95(1.65)^{\mathrm{b}}$ & \\
\hline & 2.0 & $1.20(0.18)^{\mathrm{d}}$ & $62.86(2.86)^{\mathrm{b}}$ & \\
\hline & 3.0 & $0.75(0.24)^{\mathrm{e}}$ & $69.52(3.30)^{\mathrm{a}}$ & \\
\hline & 4.0 & $0.65(0.13)^{\mathrm{e}}$ & $70.48(1.65)^{\mathrm{a}}$ & \\
\hline
\end{tabular}

Values in brackets are standard deviations; percentage values followed by the same letter are not significantly different in the same group (percentage of extractive yields) at the 0.05 level of probability; $n=5 ;{ }^{1}$ values represent the degree of difference between mass losses of the controls and the extractive tree. LC $_{50}=$ lethal concentration which causes a $50 \%$ reduction in feeding as compared to the non-treated control

Table 5 Ability of seed coat and cotyledon extracts from U. borneensis and S. longisperma to repel Coptotermis gestroi

\begin{tabular}{lcclllll}
\hline Species & Seed part & \multicolumn{5}{c}{ Repellence activity (\%) } \\
\cline { 3 - 7 } & & Control & 0.5 & 1.0 & 2.0 & 3.0 & 4.0 \\
\hline \multirow{2}{*}{ U. borneensis } & Cotyledons & $21(0.56)^{\mathrm{c}}$ & $5(0.22)^{\mathrm{d}}$ & $28(1.00)^{\mathrm{b}}$ & $33(0.42)^{\mathrm{b}}$ & $40(0.66)^{\mathrm{a}}$ & $41(1.02)^{\mathrm{a}}$ \\
& Seed coat & $21(0.82)^{\mathrm{c}}$ & $36(0.87)^{\mathrm{d}}$ & $33(1.22)^{\mathrm{d}}$ & $40(0.82)^{\mathrm{c}}$ & $53(0.11)^{\mathrm{b}}$ & $63(0.49)^{\mathrm{a}}$ \\
\multirow{2}{*}{ S. longispema } & Cotyledons & $21(0.33)^{\mathrm{c}}$ & $55(0.64)^{\mathrm{a}}$ & $51(0.56)^{\mathrm{a}}$ & $36(0.22)^{\mathrm{b}}$ & $24(1.00)^{\mathrm{c}}$ & $13(0.33)^{\mathrm{d}}$ \\
& Seed coat & $21(0.62)^{\mathrm{c}}$ & $32(0.11)^{\mathrm{a}}$ & $24(0.49)^{\mathrm{b}}$ & $24(0.33)^{\mathrm{b}}$ & $16(0.56)^{\mathrm{c}}$ & $15(0.88)^{\mathrm{c}}$ \\
\hline
\end{tabular}

Values in brackets are standard deviations; percentage values followed by the same letter are not significantly different in the same group (percentage of extractive yields) at the 0.05 level of probability; $n=3$ 
plant species could potentially be used for the preparation of termite repellent products.

Shorea longisperma seed extracts showed a reverse trend of repellency compared with $U$. borneensis. Shorea longisperma seeds showed less activity in repelling C. gestroi (Table 5). Extracts of both parts showed higher performances at $0.5 \%$ concentration ( $55 \%$ for cotyledon extract and $32 \%$ for seed coat extract) but attracted more termites when the concentration was increased. As discussed above, the effectiveness of the $S$. longispema extract may be attributed to the presence of sesquiterpenes. The presence of monoterpenes other than sesquiterpenes in $S$. longisperma seed coat extracts also makes it more repellent against C. gestroi. Monoterpenes are highly efficient as inducers of mortality or repellents against insect species (Reis et al. 2016).

\section{CONGLUSIONS}

Upuna borneensis seeds contained higher levels of extractives compared with $S$. longisperma seeds. Upuna borneensis seed coat extract effectively repelled termites, but did not cause high termite mortality. Cotyledon extract of $S$. longisperma attracted and killed termites even at the lowest concentration. Hence, extract of $S$. longisperma cotyledon could potentially be used as wood preservative. It was effective against termites even at the lowest concentration compared with the rest of the samples (S. longisperma seed coat, $U$. borneensis cotyledon and $U$. borneensis seed coat). Evaluation of efficiency, stability and production costs of seed coat and cotyledon extracts as wood preservatives need to be investigated.

\section{ACKNOWLEDGEMENTS}

We gratefully acknowledge the FRIM Research Project grant (No. 41310404005). We also thank Zaini S, Zaitihaiza K. Mohd-Faridz Z, Norziah $\mathrm{I}$ and Hanizah $\mathrm{H}$ for assistance in sample preparation and seed extraction.

\section{REFERENCES}

Abbas K \& Tahere R. 2012. Chemical composition and insecticidal activity of essential oil from Coriandrum sativum seeds against Tribolium confusum and Callosobruchus maculatus. ISRN Pharmacology 2012: 1-5. https://doi.org/10.5402/2012/263517.

Аввотт WS. 1925. A method of computing the effectiveness of an insecticide. Journal of Economic Entomology 18: 265-267.
ADAM RP. 2001. Identification of Essential Oils Components by Gas Chromatography/Mass Spectroscopy. Third edition. Allured Publishing Corporation, Carol Stream.

Addisu S, Mohamed D \& Waktole S. 2014. Efficacy of botanical extracts against termites, Macrotermes spp., (Isoptera: Termitidae) under laboratory conditions. International Journal of Agricultural Research 9: 60-73.

Ainetasham AA, Bilal N-E-H, \& XaAceph M. 2016. Efficacy of seed extracts (Mentha arvensis, Ocimum bacilicum, Psyllium ovata, Cichorium intybus) against Coptotermes heimi (Wasmann). Biologia 62: 103-109.

ASTM (American Society for Testing and Materials). 2001. Standard method for preparation of extractive-free wood. Part 22. ASTM D1105-96. Pp 205-206 in ASTM Annual Book of Standards. Volume 4.10-Wood. ASTM, West Conshohocken.

Antwi-Bonsiako C \& Damoah A. 2010. Investigation of synergistic effects of extracts from Erythrophleum suaveolens, Azadirachta indica and Chromolaena odorata on the durability of Antiaris toxicaria. International Biodeterioration and Biodegradation 64: 97-103.

Cornelius ML \& LAX AR. 2005. Effect of summon preferred food source on feeding, tunneling, and bait station discovery by the Formosan subterranean termite (Isoptera: Rhinotermitidae). Journal of Chemical Ecology 98: 502-508.

Dalia AB. 2011. Insecticidal and antifeedant activities and chemical composition of Casimiroa edulis La Lave and Lex (Rutaceae) leaf extract and its fractions against Spodoptera littoralis larvae. Australian Journal of Basic and Applied Sciences 5: 693-703.

Finney DJ. 1971. Probit Analysis. Third edition. Cambridge University Press, Cambridge.

George DR, Finn RD, Graham KM \& Sparagano OAE. 2014. Present and future potential of plant-derived products to control arthropods of veterinary and medical significance. Parasites $\mathcal{E}$ Vectors 7: 28-39

Hassan B, Mankowski ME, Kirker G \& Sohail A. 2017. Effects of heartwood extractives on symbiotic protozoan communities and mortality in two termite species. International Biodeterioration and Biodegradation 123: 27-36.

Hassan B, Mankowski ME, Kirker GT, Clausen CA \& Ahmed S. 2018. Effects of white mulberry (Morus alba) heartwood extract against Reticulitermes flavipes (Blattodea: Rhinotermitidae). Journal of Economic Entomology 111: 1337-1345.

Iто T. 2011. Structures of oligostilbenoids in dipterocarpaceaeous plants and their biological activities. Yakugaku Zasshi 13: 93-100.

Ito T, Furusawa M, TANaKa T ET AL. 2005. Resveratrol derivatives from Upuna borneensis. Chemical and Pharmaceutical Bulletin 53: 219-224.

Janaki S, Zandi-Sohani N, Ramezani L \& Szumny A. 2018. Chemical composition and insecticidal efficacy of Cyperus rotundus essential oil against three stored products pests. International Biodeterioration and Biodegradation 133: 93-98.

Kirton LG, Brown VK \& Azmi M. 1998. A new method of trapping subterranean termites of the genus Coptotermes (Isoptera: Rhinotermitidae) for field and laboratory studies. Sociobiology 32: 451-458.

McDonald LL, Guy RH \& Speirs RD. 1970. Preliminary Evaluation of New Candidate Materials as Toxicants, 
Repellents and Attractants Against Stored Product Insects. Marketing Research Report No. 882. US Department of Agriculture, Washington.

Olugbemi B. 2012. Termiticidal activity of Parkia biglobosa (Jacq) Benth seed extracts on the termite Coptotermes intermedius Silvestri (Isoptera: Rhinotermitidae). Psyche 2012: 2-5.

Reis SL, Mantello AG, Macedo JM et al. 2016. Typical monoterpenes as insecticides and repellents against stored grain pests. Molecules 21: 258-267. https:/ / doi: $10.3390 /$ molecules21030258.

Roszaini K \& Hale M. 2019. Biocidal potential of the extractives of four Malaysian timbers against subterranean termites and wood decay fungi. European Journal of Wood and Wood Products 77: 147155. https// doi.org/10.1007/s00107-018-1361-5.

Roszaini K, Nor Azah MA, Mailina J, Zaini S \& Mohammad FARID Z. 2013. Toxicity and antitermite activity of the essential oils from Cinnamomum camphora, Cymbopogan nardus, Melaleuca cajuputi and Dipterocarpus sp. against Coptotermes curvignathus. Wood Science Technology 47: 1273-1284. https//doi 10.1007/s00226-013-0576-1.

Roszaini K, Nor Azah MA, Zaini S \& Zaitihaiza K. 2014. Antitermitic potential of heartwood and bark extract and chemical compounds isolated from Madhuca utilis Ridl. H. J. Lam and Neobalanocarpus heimii King P. S. Ashton. Holzforschung 68: 713-720.

SAmbangi P \& Rani PU. 2016. Physicological effects of resveratrol and coumaric acid on major ground nut pests and their egg parasitoid behaviour. Archives of Insect Biochemistry and Physiology 91: 230-245.

Sbeghen AC, Dalfovo V, Serafini LA \& Monteriro de Barros N. 2002. Repellence and toxicity of basil, citronella, ho-sho and rosemary oils for the control of the termite Cryptotermes brevis (Isoptera: Kalotermitidae). Sociobiology 40: 585-593.

Schultz TP \& Nicholas DD. 2000. Naturally durable heartwood: evidence for a proposed dual defensive function of the extractives. Phytochemistry 54: $47-52$.

Singh N \& Sushilkumar A. 2008. Anti termite activity of Jatropha curcas Linn. biochemicals. Journal of Applied Sciences and Environmental Management 12: 67-69.

SINGH T \& SINGH AP. 2012. A review of natural products as wood protectant. Wood Science and Technology 46: 851-870.

Soepadmo E, SAw LG \& Chung RCK. 2002. Tree Flora of Sabah and Sarawak. Volume 4. Forest Research Institute Malaysia, Kepong.

Sullamy DGA, Carla FP, Jonny EDL et al. 2011. Insecticidal activity of three species of Guatteria (Annonaceae) against Aedes aegypti (Diptera: Culicidae). Revista Colombiana de Entomología 37: 262-268.

Wong TM. 1982. A Dictionary of Malaysian Timbers. Revised by Lim SC \& Chung RCK. Malayan Forest Records No. 30. Forest Research Institute Malaysia, Kepong.

Xu C, Pranovich A, Hemming Jet al. 2009. Hydrolytic stability of water soluble spruce $O$-acetyl galactoglucomannans. Holzforschung 63: 61-68.

YANG DQ. 2009. Potential utilization of plant and fungal extracts for wood protection. Forest Products Journal 59: 97-103.

Yong WSY, Chua LSL, Suhaida M \& Aslina B. 2011. Forest Research Institute Malaysia: A Sanctuary for Threatened Trees. FRIM Research Pamphlet No. 130. Forest Research Institute Malaysia, Kepong. 